\title{
Testing of Method for Assessing of Room Thermal Stability
}

\author{
Hana Charvátová ${ }^{1, \star}$ and Martin Zálešák ${ }^{2}$ \\ ${ }^{1}$ Tomas Bata University in Zlín, Faculty of Applied Informatics, Regional Research Centre CEBIA-Tech, nám. T. G. \\ Masaryka 5555, 76001 Zlín, Czech Republic \\ ${ }^{2}$ Tomas Bata University in Zlín, Faculty of Applied Informatics, Department of Automation and Control Engineering, nám. T. G. \\ Masaryka 5555, 76001 Zlín, Czech Republic
}

\begin{abstract}
The paper presents the interim results of our research on the developing methodological procedure which could be used for assessment of a thermal stability of buildings with regards to its thermal accumulative parameters. The principle of testing is based on a combination of computer simulation of cooled room model developed in COMSOL Multiphysics software and on theoretical calculations with respect to compliance with valid European and Czech technical standards used in building industry and architecture under conditions obtained by real measurement for the room to be tested. The presented example shows the effect of the heataccumulation properties of the outside wall insulation materials on the course of the cooling room for winter conditions.
\end{abstract}

\section{Introduction}

Each residential building is characterized by energy consumption and energy gains. The energy demands depend on many factors such as the climatic conditions, the purpose of the object, and hence the requirements of the indoor environment, and so on. In terms of optimization, the design of the buildings is emphasis on minimizing energy consumption while minimizing investment and operating costs while keeping the required internal environment parameters. These costs strongly depend on the building's thermal storage parameters and can therefore be influenced by their construction.

However, due to the complexity of physical processes, a theoretical testing of the thermal stability in the design of new building structures or in their reconstruction is very difficult. In terms of the assessment of the heat accumulation parameters, consideration should be given to the time delay of the response of the indoor environment to changing outdoor conditions. These problems are solved in the technical standard CSN EN 13790 [1] and related CSN EN 13792 [2], CSN EN 13786 [3], CSN EN 15251 [4] and CSN 060220 [5] and, to a certain extent, CSN 730540 [6].

However, a complex solution to this problem according to CSN EN 13790 [1] and related standards is difficult and the most accurate methods are sought using modern computer tools using simulation methods based on numerical solution of non-stationary multiphysical processes on models describing studied objects under simplified conditions.

From this perspective, we deal with testing of the factors that influence thermal stability of building by com-

\footnotetext{
^e-mail: charvatova@fai.utb.cz
}

bination of computer simulation in the COMSOL Multiphysics user interface and theoretical calculations with respect to above-mentioned technical standards used in the building industry. Possibilities of use Comsol Multiphysics for testing of thermal stability of buildings were verified in the papers [7], [8].

In the following text, we follow the paper [8], in which the heat flow through the uninsulated outside wall were compared by the theoretical calculation. Now, we describe the procedure by which it is possible to combine both computer simulation and theoretical calculations to determine the heat losses of the room to be taken under simplified assumptions for the assessment of thermal insulating materials of the external wall or the heat-accumulation properties of the room to be tested.

\section{Theoretical description of the studied problem solving}

For computer simulation by COMSOL Multiphysics software we use Laminar Flow Interface of the Conjugate Heat Transfer Module, which is used primarily to model slowmoving flow in environments where temperature and energy transport are also an important part of the system and application, and must coupled or connected to the fluidflow in some way. The interface solves the Navier-Stokes equations together with an energy balance assuming heat flux through convection and conduction. The density term is assumed to be affected by temperature and flow is always assumed to be compressible [9]. 


\section{Finite Element Equations for Heat Transfer}

A basic equation of non-stationary heat transfer in an isotropic body can be described by equation (1) [10]:

$$
-\left(\frac{\partial q_{x}}{\partial x}+\frac{\partial q_{y}}{\partial y}+\frac{\partial q_{z}}{\partial z}\right)+\Phi=\varrho c_{p} \frac{\partial T}{\partial t}
$$

where:

$q_{x}, q_{y}, q_{z}$ - components of heat flow density, $\left[\mathrm{W} \cdot \mathrm{m}^{-2}\right]$;

$\Phi=\Phi(x, y, z, t)$ - inner heat-generation rate per unit volume, $\left[\mathrm{W} \cdot \mathrm{m}^{-3}\right]$;

$\varrho$ - material density, $\left[\mathrm{kg} \cdot \mathrm{m}^{-3}\right]$;

$c_{p}$ - heat capacity, $\left[\mathrm{J} \cdot \mathrm{K}^{-1}\right]$;

$T$ - temperature, [K];

$t$ - time, [s].

According to Fourier's law the components of heat flow can be expressed as follows [10]:

$$
q_{x}=-\lambda \frac{\partial T}{\partial x}, q_{y}=-\lambda \frac{\partial T}{\partial y}, q_{z}=-\lambda \frac{\partial T}{\partial z}
$$

where:

$\lambda$ - thermal conductivity of the media, $\left[\mathrm{W} \cdot \mathrm{m}^{-1} \mathrm{~K}^{-1}\right]$.

Substitution of Fourier's relations (2) into equation (1) gives the basic heat transfer equation [10]:

$$
\frac{\partial}{\partial x}\left(\lambda \frac{\partial T}{\partial x}\right)+\frac{\partial}{\partial y}\left(\lambda \frac{\partial T}{\partial y}\right)+\frac{\partial}{\partial z}\left(\lambda \frac{\partial T}{\partial z}\right)+\Phi=\varrho c_{p} \frac{\partial T}{\partial t}
$$

It is assumed that the boundary conditions can be of the following types [10]:

1. Specified temperature: $T_{s}=T_{1}(x, y, z, t)$ on $S_{1}$.

2. Heat flow density: $q_{s}=q(x, y, z, t)$ on $S_{2}$.

3. Convection boundary conditions: $q_{x} n_{x}+q_{y} n_{y}+$ $q_{z} n_{z}=h\left(T_{s}-T_{e}\right)+q_{r}$ on $S_{3}$.

where:

$h$ - heat transfer coefficient, $\left[\mathrm{W} \cdot \mathrm{m}^{-2} \mathrm{~K}^{-1}\right]$;

$T_{s}$ - unknown surface temperature, $[\mathrm{K}]$;

$T_{e}$ - convective exchange temperature, $[\mathrm{K}]$;

$q_{s}$ - heat flow density on the surface, $\left[\mathrm{W} \cdot \mathrm{m}^{-2}\right]$;

$q_{r}$ - incident radiant heat flow per unit surface area, $\left[\mathrm{W} \cdot \mathrm{m}^{-2}\right]$

$q_{x}, q_{y}, q_{z}$ - components of heat flow density, $\left[\mathrm{W} \cdot \mathrm{m}^{-2}\right]$.

For initial temperature field for a body at the time $\tau=0$ it holds [10]:

$$
T(x, y, z, t)=T_{0}(x, y, z)
$$

By determination of the heat losses from the room we assumed that the heat transfer between the room air and the surroundings is the heat transfer through its walls.
In this case, the heat flow can be described by equation (7) [5]:

$$
\Phi=A \cdot U\left(\theta_{\text {in }}(t)-\theta_{\text {out }}(t)\right),
$$

where:

$A$ - heat transfer surface, $\left[\mathrm{m}^{2}\right]$;

$U$ - overall heat transfer coefficient, $\left[\mathrm{W} \cdot \mathrm{m}^{-2} \mathrm{~K}^{-1}\right]$;

$\theta_{\text {in }}$ - temperature of air inside the room, $\left[{ }^{\circ} \mathrm{C}\right]$;

$\theta_{\text {out }}$ - temperature of air outside the room, $\left[{ }^{\circ} \mathrm{C}\right]$;

$\Phi$ - heat flux through the external wall, [W];

$t$ - time, [s].

The overall heat transfer coefficient $(U)$ through the multilayer wall of the room can be computed according to equation (6) [5]:

$$
U=\frac{1}{\frac{1}{h_{\text {in }}}+\frac{1}{h_{\text {out }}}+\sum_{j=1}^{n} \frac{\delta_{j}}{\lambda_{j}}}
$$

where:

$h_{\text {in }}$ - heat transfer coefficient of the inner wall surface, $\left[\mathrm{W} \cdot \mathrm{m}^{-2} \mathrm{~K}^{-1}\right]$;

$h_{\text {out }}$ - heat transfer coefficient of the outside wall surface, $\left[\mathrm{W} \cdot \mathrm{m}^{-2} \mathrm{~K}^{-1}\right]$

$U$ - heat passage coefficient, $\left[\mathrm{W} \cdot \mathrm{m}^{-2} \mathrm{~K}^{-1}\right]$;

$\delta_{j}$ - thickness of the layer, [m];

$\lambda_{j}$ - thermal conductivity of the layer, $\left[\mathrm{W} \cdot \mathrm{m}^{-1} \mathrm{~K}^{-1}\right]$;

$n$ - number of the layers, [-].

The degree of utilization of heat gains or thermal heat losses are directly related to the thermal inertia of the building. Based on the inner heat capacity of the building, a time response to changing environmental conditions can be determined as a time constant, which generally indicates the time at which the transient process of a monitored variable decreases from maximum to zero value, if the process proceeds at constant velocity or linearly.

According to the Czech technical standard CSN EN ISO 13790 [1], the time constant for cooling mode is given by the equation (7):

$$
\tau_{c}=\frac{C_{m} / 3.6}{H_{t r, a d j}+H_{v e, a d j}},
$$

$\tau_{c}$ - time constant of the building or building zone in the cooling mode, [h];

$C_{m}$ - inner heat capacity of the building, $\left[\mathrm{kJ} . \mathrm{K}^{-1}\right]$;

$H_{t r, a d j}$ - representative value of the total specific heat flux by heat transfer converted for a thermal difference between the interior and the external environment, [W. $\left.\mathrm{K}^{-1}\right]$. $H_{v e, a d j}$ - representative value of the total specific heat flux by ventilation converted for a temperature difference between the interior and the external environment, [W. $\mathrm{K}^{-1}$ ]. 


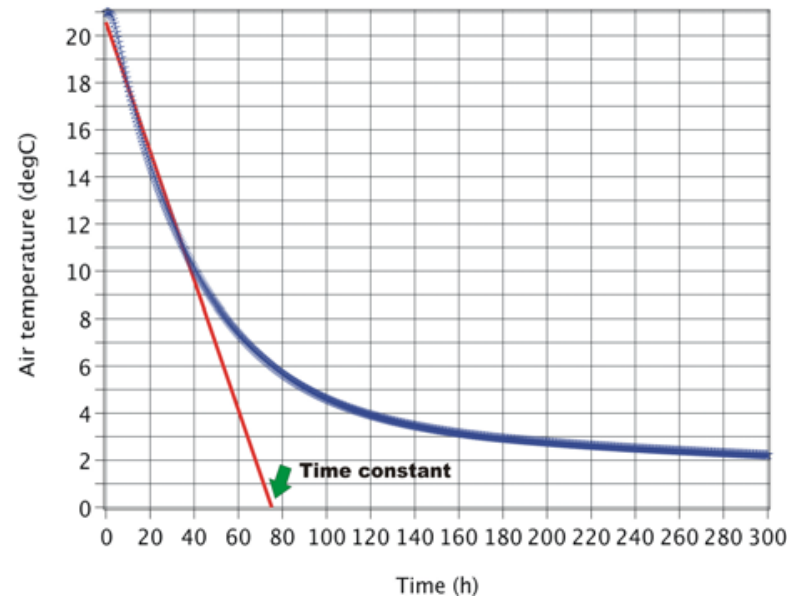

Figure 1. Principle of determining the time constant in the case of cooling down of the room.

It is obvious that the time course of heating or cooling of the room strongly depends on the outside air temperature. In this regard, it is necessary to consider the thermal accumulation properties of the room, as a result of which the response of the indoor environment is caused by some time delay in the changing environment conditions. Therefore, an effort is made to simplify the solution, for example by expressing the storage properties of a building by room time constant according to CSN 060220 [5] or by so-called sliding temperature running mean external temperature according to CSN EN 15251 (8) [4]:

$$
\theta_{r m}=(1-\alpha)\left\{\theta_{e d-1}+\alpha \cdot \theta_{e d-2}+\alpha^{2} \cdot \theta_{e d-3} \ldots\right\},
$$

or by equation (9):

$$
\theta_{r m}=(1-\alpha) \theta_{e d-1}+\alpha \cdot \theta_{r m-1} .
$$

$\theta_{r m}$ - running mean external temperature for the evaluated day, $\left[{ }^{\circ} \mathrm{C}\right.$,

$\theta_{r m-1}$ - running mean external temperature for the previous day, $\left[{ }^{\circ} \mathrm{C}\right]$,

$\theta_{e d-1}$ - daily mean external temperature for the previous day, $\left[{ }^{\circ} \mathrm{C}\right]$,

$\theta_{e d-2}$ - daily mean external temperature two days before the evaluated day, $\left[{ }^{\circ} \mathrm{C}\right]$,

$\theta_{e d-3}$ - daily mean external temperature three days before the evaluated day, $\left[{ }^{\circ} \mathrm{C}\right]$,

$\alpha$ - coefficient from 0 to 1 . Its recommended value is 0.8 , [1].

The aim of our research is to find a relationship between the time constant and the constant $\alpha$.

\section{Method used for the studied problem solving}

Our currently tested principle for assessing of the room thermal stability using the theoretical calculations and computer simulations supported by experimental measurements in laboratory or real conditions is based on these steps:

- Build a simplified model of the tested room in user interface of COMSOL Multiphysics.

- Computer simulation of temperature distribution in the tested model of the room for 9 days with the initial and boundary conditions obtained by measuring on a real object of the room (the course of the outdoor air temperature, or the ambient air temperatures, if any, of the adjoining rooms).

- Exporting data describing the air temperature at the center of the room calculated in COMSOL Multiphysics to the user interface of software Maple, where the time constant is determined by Least square method from the linear part of the curve of temperature decrease (see Fig. 1).

- Numerical determination of the optimal value of the coefficient $\alpha$ for calculating the running mean external temperature according to equation (8) or (9) and then the heat loss through the outside wall of the room after 8 days of testing so that the heat losses calculated according to [5] equal to the heat losses determined by the computer simulation.

\subsection{Example of the suggested method using}

We demonstrate the above described method for assesment of thermal stability of the room which simplified geometric model is shown in Fig. 2. It contains only elements that significantly affect the heat flow between the rooms and the surroundings.

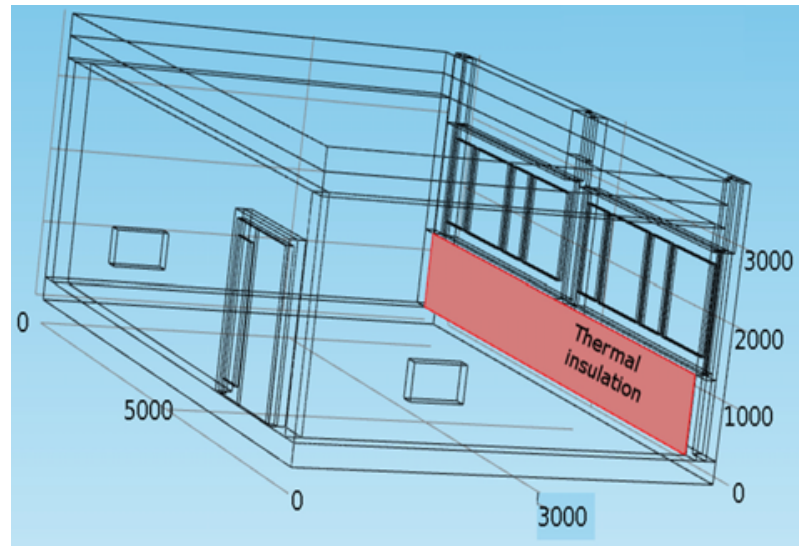

Figure 2. Geometry sketch of the tested room model. 
Table 1. Physical properties of the main geometrical elements of the tested room.

\begin{tabular}{lccc}
\hline $\begin{array}{l}\text { Geometrical } \\
\text { element }\end{array}$ & $\begin{array}{c}\text { Thermal } \\
\text { conductivity } \\
{\left[\mathrm{W} \cdot \mathrm{m}^{-1} \cdot \mathrm{K}^{-1}\right]}\end{array}$ & $\begin{array}{c}\text { Density } \\
{\left[\mathrm{kg} \cdot \mathrm{m}^{-3}\right]}\end{array}$ & $\begin{array}{c}\text { Specific } \\
\text { heat capacity } \\
{\left[\mathrm{J} \cdot \mathrm{kg}^{-1} \cdot \mathrm{K}^{-1}\right]}\end{array}$ \\
\hline Inner and external walls & 0.1765 & 817 & 953 \\
Floor & 1.43 & 2300 & 1020 \\
Ceiling & 0.8185 & 1251 & 1021 \\
Window frame & 0.20 & 420 & 2510 \\
Ceiling insulation & 0.039 & 30 & 1270 \\
Thermal insulation of external wall & 0.18 & 400 & 5000 \\
\hline
\end{tabular}

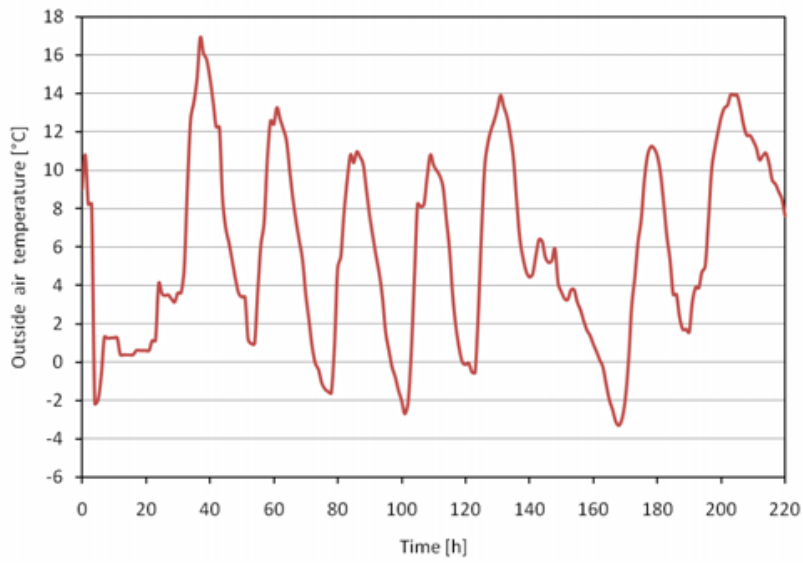

Figure 3. Course of outside air temperature used for computer simulation - measured data.

Aim of the testing was to evaluate the influence of the thickness of the external wall and its thermal insulation on the time course of the cooling down of the room. The conditions used for computer simulation and theoretical calculations are:

- initial air temperature inside the room $21^{\circ} \mathrm{C}$,

- air temperature of all neighboring rooms $0^{\circ} \mathrm{C}$,

- heat transfer coefficient between the walls of the room and the air inside the building $8 \mathrm{~W} \cdot \mathrm{m}^{-2} \cdot \mathrm{K}^{-1}$,

- heat transfer coefficient between the walls of the room and outside air $23 \mathrm{~W} . \mathrm{m}^{-2} \cdot \mathrm{K}^{-1}$,

- thickness of the inner walls, ceiling and floor was $30 \mathrm{~cm}$,

- physical properties of all elements of the models shows Table 1,

- course of outside air temperature is shown in Fig. 3.

The results of our experiment are presented in Figs 4 6. Fig. 4 shows a decrease of the air temperature inside the room during its cooling down in dependence on the thermal insulation thickness. Simulations were compared for wall of $200 \mathrm{~mm}$ thickness. It is evident, that maximum temperature decrease occurred for the wall without thermal insulation and that the temperature drop has decreased with the increasing thickness of the thermal insulation.

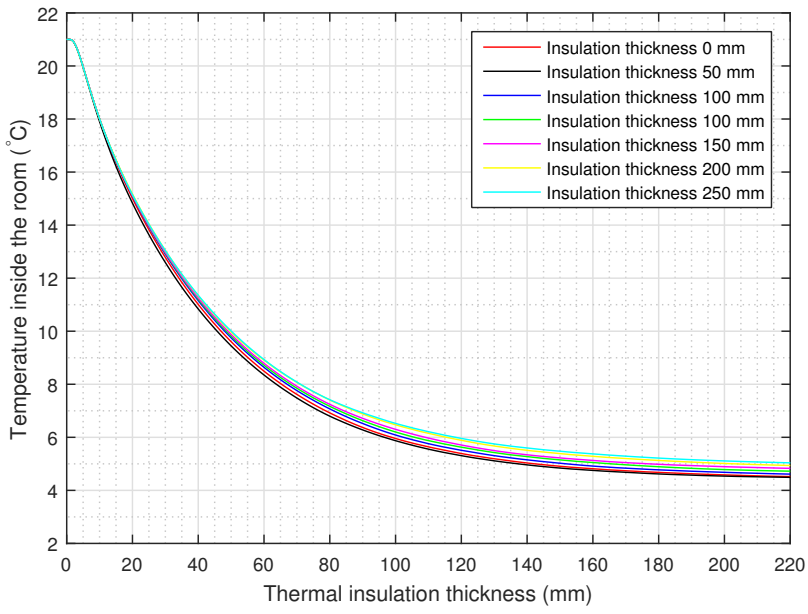

Figure 4. Dependence of the air temperature decrease on thickness of the external wall insulation.

The dependence of the time constants on the thermal insulation determined by the linear regression of the data obtained by computer simulation is shown in Fig. 5. The time constant is increased approximately by 4.6 hours for the wall with thermal insulation thickness of $300 \mathrm{~mm}$ compared to the time constant for the room without the thermal insulated external wall.

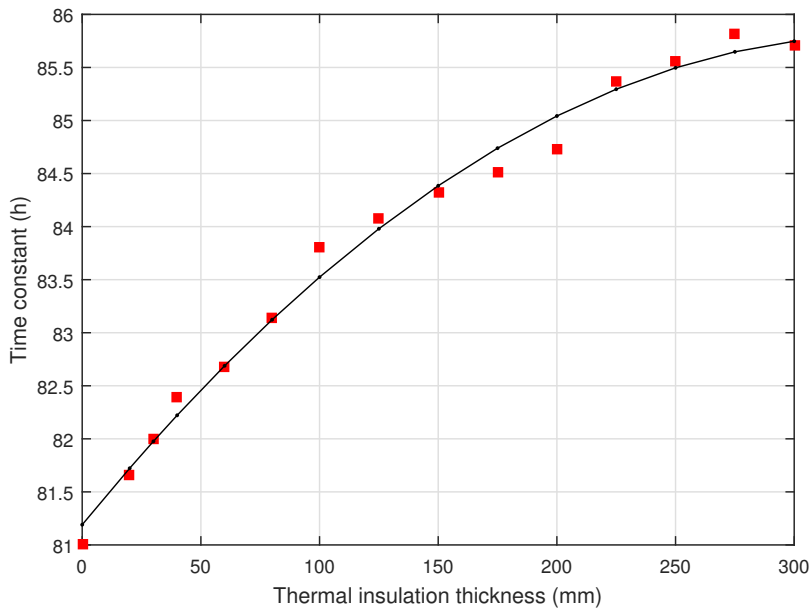

Figure 5. Dependence of the time constant $\tau_{c}$ on thickness of the external wall insulation. 
In Fig. 6 is presented dependence of the thermal insulation on value of coefficient $\alpha$ which is required to calculate the daily mean temperature of the external air (8) or (9) in accordance with CSN EN 15251 [4]. It is evident that if the wall be insulated by material with higher specific heat capacity, the air temperature and the time of cooling down the room increase. The experimental results show that under the conditions considered, the coefficient $\alpha$ strongly depends on the thickness of the external wall thermal insulation. Under the tested conditions, its recommended value of 0.8 [4] is achieved up to a thickness of thermal insulation of about $50 \mathrm{~mm}$.

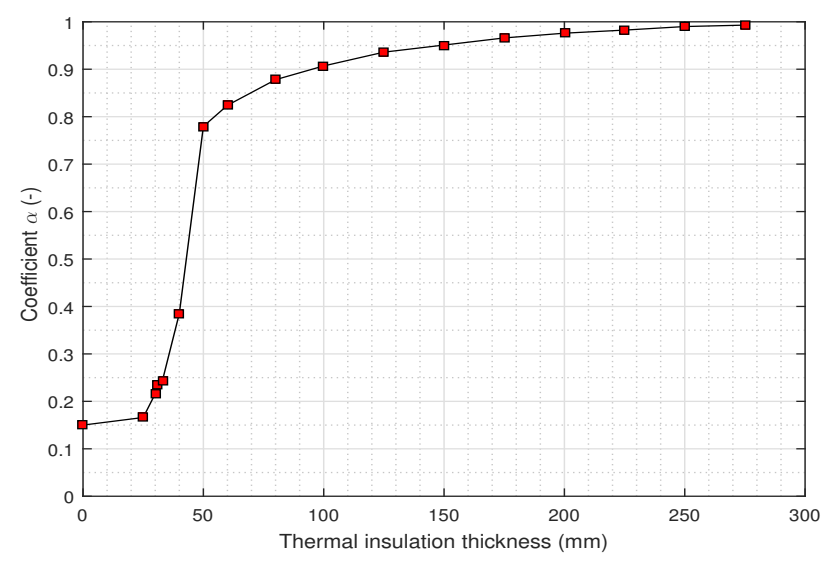

Figure 6. Dependence of the coefficient $\alpha$ on thickness of the external wall insulation.

\section{Conclusion}

In the paper was described the procedure by which it is possible to combine both computer simulation and theoretical calculations to determine the heat losses of the room under simplified assumptions with respect to Czech and European technical standards used in construction and architecture. The methodology was tested by the assessment of the heat-accumulation properties and thermal insulating materials of the external wall. The tested model of the room showed dependence of the time constant $\tau_{c}$ and the coefficient $\alpha$ on the thermal insulation thickness.

Further work will be focused on verifying the validity of our procedure for other boundary conditions as well as for other types of construction structures.

\section{Acknowledgement}

This work was supported by the Ministry of Education, Youth and Sports of the Czech Republic within the National Sustainability Programme project No. LO1303 (MSMT-7778/2014).

\section{References}

[1] CSN EN 13790: Energy performance of buildings Calculation of energy use for space heating and cooling (Office for Standards, Metrology and Testing, 2009)

[2] CSN EN 13792: Thermal performance of buildings Calculation of internal temperatures of a room in summer without mechanical cooling - Simplified methods. (Czech Standards Institute, Prague, 2005)

[3] CSN EN 13786: Thermal performance of building components - Dynamic thermal characteristics - Calculation methods (Office for Standards, Metrology and Testing, 2008)

[4] CSN EN 15251: Indoor environmental input parameters for design and assesment of energy performance of buildings - addressing indoor air quality, thermal environment, lighting and acoustics. (Office for Standards, Metrology and Testing, Prague, 2011)

[5] CSN 06 0220: Heating systems in buildings - Dynamic behaviour. (Czech Standards Institute, Prague, 2006)

[6] CSN 73 0540: Thermal protection of buildings (Office for Standards, Metrology and Testing, Prague, 2011)

[7] V. Gerlich, Verification of Possibility of Using COMSOL Multiphysics as Simulation Tool for Heat Transfer Calculation in Systems with Accumulation. (Thesis. Tomas Bata University in Zlin, Zlin, 2012) pp. 157

[8] H. Charvátová, M. Zálešák Proceedings of the 19th International Conference on Systems. Recent Advances in Systems, (Zakynthos Island, Greece: WSEAS Press, 2015) pp. 627-631

[9] Heat Transfer Module User's Guide. (COMSOL, 2012) pp. 296

[10] G. Nikishkov, Introduction to the Finite Element Method. (University of Aizu, 2003)

[11] H. S. Carslaw, J. C. Jaeger, Conduction of Heat in Solids. (Clarendon Press, Oxford, 1986) pp. 510 